\title{
Study on the Effect of Visual Symbols and Elements on Web Interface Design
}

\author{
-Discount Network Interface Design of Wei Yijia \\ Guoman Yao ${ }^{1, a}$, Haichao Wang ${ }^{2, b}$ \\ ${ }^{1,2}$ Department of Fine Arts, Chongqing University of Education, Chongqing, 400067 \\ a email, ${ }^{b}$ email
}

Keywords: Web Interface; Design; Visual Symbol; Element, Wei Yijia

\begin{abstract}
The use of web design elements create visual symbol timing, can make the web interface design and aesthetic quality to be improved to meet the information transfer requirements also should focus on the transfer process graphic viewer demand for the visual aesthetic, and therefore, enhance understanding of research design, visual web interface symbol element is particularly important. Through the web interface design common problems were analyzed and summarized and visual symbolic elements in web interface design use, visual impact Wei Yijia element symbol web interface visual design of a preliminary study.
\end{abstract}

\section{Introduction}

In today's popular network of various types of web design endless variety allows viewers dizzying, but an overview of the overall situation in which the majority of web interface design gives a distinct lack of personality, lack of interest, the web interface template pattern over a single sense of monotony, and interface design or page layout over the pursuit of beauty and frills hampered web interface browsing, information inquiry and functional requirements. Decide a web site interface design factors of success are often the perfect combination of technology and art can not be separated web design, so as not to leave open the visual element symbols web interface of cognitive and rational use. With today's society people's material standard of living improved, the public about the humanistic spirit and desire to pursue more attention, which requires the use of web interface design elements of visual symbols have a deeper understanding and a more reasonable fine sensibility of the control. This not only helps to get rid of web interface design "stereotyped" or "too complicated" defects, but also conducive to the web interface to watch and perfect combination of functionality, to meet the visual aesthetic enjoyment of the majority of viewers.

\section{A Web Design and Visual Symbol Element}

Web page (Web Page) is the basic elements of the Internet site is the site that hosts a variety of application information large platform. Popular website that is a combination of various pages of information carrier, a Web site only if the domain name and web hosting without making any page, viewers are unable to access the site properly. Text and graphic images are the most basic elements that constitute the web interface of the two, to be unbundled text can be seen as the content of the page, and the graphic image is beautiful in charge of website pages, in addition to several other pages constituting key elements also include animation and special effects, page layout and color, and other programs. Web design is under binding pages each base element conditions in the function defined circumstances, through a more rationalized, sophisticated technology for web interface colors, text, graphics, images, panel layout in line with the Company, page design business website needs, helping corporate website clear and effective delivery of our products, ideas, services, and cultural and other information to the viewer. Nice web interface design company is an important factor in the Internet enterprises to enhance the brand image of a website is to promote the success of the indispensable conditions.

Within the scope of our lives, everywhere you can see a wide variety of visual symbolic 
elements, they work in our lives all the time does not play a significant role. Through our eyes have seen, we observed some small things or are both subtle logo can be summarized as "visual symbol element." They play a lot of role in our social life, such as: warning indicator, intersection, labeling, promotional materials and so on. After the above mentioned things are through our visual observation, thinking and analysis through the brain tissue, can our ideas, influence and change the behavior of the visual element symbol. Website interface design as to convey the company, corporate thinking media itself is a means of symbols, and its transmission is mainly through the web interface design, visual symbol elements, such as graphics, text, color and other design organizations and layout, to achieve the transfer to be expression, publicity companies connotation purposes. Thus, in modern web interface design, use of visual symbols of elements for website design has a crucial importance.

With the progress of time, the network has become an important way of modern information transmission, but also modern life become an indispensable part of people for web design of visual function symbol element produced a requirement for visual symbols web elements artistic, aesthetic pursuit of rising, this also led to an increase of aesthetic standard web interface design. Each web interface designer only visual elements through a combination of creative and planning, the use of reasonable good visual process architecture appropriate visual guide, master of color design used, that is more reasonable personalized web interface with a strong visual impact, web interface in order to further achieve the role of information passed on to win the competition in the thousands.

\section{The Web Interface Design Problems}

As people rely on the use of the Internet network, the major enterprises and companies increasing emphasis on advocacy network marketing model, people are no longer confined to the traditional way of doing business, the traditional trading patterns Reflecting being gradually emerging e-commerce form affected. With the rise in recent years, various types of e-commerce sites, all kinds of various types of web interface design are endless. An overview of the overall situation but, in general, most e-commerce sites to escape the rigid unified web interface design, web interface design patterns too and simplification. The lack of a specific corporate website interface design, personalization and uniqueness, gives a sense of monotony, can not form a strong visual impact on the viewer and memory. Such as Taobao, the only product, pat network web interface design, although better meet customer functional Internet browsing, and operational needs, but in art and design pages on the lack of artistry, unique, easy to give in dull impression.

The web interface of a single individual is in stark contrast to commercial sites do not focus on web interface design layout, any placement will be a variety of text, images and other elements of visual symbols without considering at the interface, giving congestion, crowded plug and chaotic visual experience. Entire web interface design is too complicated, it will seriously hamper the viewer to observe the information on the website and find the required information during operation encountered many obstacles. It not only failed to functional website web interface to play, but also gives the website information is missing, the whole messy style, brand image is not uniform untidy feeling.

Common sites from the web interface design is easy to see two kinds of problems, causing serious problems on the web design is the key to the site on the grid interface designer for artistic design and functionality of the lack of awareness. As a comprehensive reading literary master said: "Literature should be like a dance in shackles, chains are metrical, metrical we want to go along, but not subject to restraint, to dance in shackles own dance." Literature thus, web interface design is the same. Unlike other plane layout design, web interface design from the outset, subject to certain technical conditions limit, but requires the designer in this context in the web interface design, visual symbol of the control element has a delicate, just the right, to meet the site's premise web interface functionality, web interface gives the site unique ornamental art. Only when the website web interface functionality and artistry can be satisfied in order to play the maximum benefit out of the site, giving viewers enjoy the beauty of the visual experience. 


\section{The Visual Symbols and Elements in Web Interface Design}

For a good web site for the formation of interface design forum, inseparable from the visual symbol element design use. Web interface is composed of all kinds, large and small elements of visual symbols according to certain rules, designed to create the layout formation. We have seen all kinds of different forms in the Internet web interface for its use in the form of a visual symbol element design, means and methods vary, but in general the web interface design process has always been inseparable font, graphics, color pages constitute the three basic elements of visual symbols of sophisticated design use.

The main function of text on the page is to help the website, the company better communicate relevant information to viewers, but to do validity of the information conveyed must consider whether the overall effect of the text editor to give people a clear visual impression, can not be modeling and editing the text itself upside ignore function is to convey the theme of content and presentation of information. At the same time, the text layout is not exist in isolation, in the text of the page orchestrated designer should first do is to understand better the role of web interface design and site-related corporate culture, to understand the target audience website and Scope and so, although it can be used to pass information image label, but the text in the transmission process status is irreplaceable. Good site web interface for text fonts do graphical expression, artistic expression, not only form a unique, personalized visual symbolic elements exist, but also to attract attention to distinguish between the viewer and the other pages to increase site Attention. Rational use, to make the text clear text layout in web interface, clear distribution of the remarkable emotional appeal but will also inform the public passed.

In web design, the status of the picture behind the text. Good graphics can quickly cause the viewer's interest, but also the site more unique, Marked. In a fast-paced society people has entered the era of pictures, good graphics in eye-catching but also has helped viewers across racial, language barriers browse exchanges. Figure refers to Italy, through a simple and easy to understand graphics and guide people to transfer information. On paper media viewer for image printing effect, demanding clarity, but the web interface is different from its image requirements are very low, and the viewer's eye can not clearly distinguish whether the image is processed with great precision, the designer only We need to consider how to reduce the file size of the image, how the size of the image is reasonable to control. Image information can be expressed simplistic, giving the viewer a more intuitive visual experience, this text can not be achieved. Although it can not fully bring to the role of text, but the image text layout was sublime, it may be a web interface more compelling, intricate and colorful, to give the viewer left a deeper impression.

Color plays an important role in modern life, and our lives. Color fully into life and become a symbol of modern life, not only can affect people of color perception, feeling, memory, association, etc., but also produce a certain psychological suggestion, resonance and appeal. American psychologist Xi Lu contemporary visual art ink once said: "colors evoke emotions, express feelings, and even affect our normal physiological feelings." Therefore, the use of web interface design should be based on the color of the different audiences and different the main product to be used should be consistent with the color of the corresponding guide human emotional design use, such as green gives a sense of the vitality of quiet, peace and reminiscent of Enron. Red, orange, yellow and other warm colors colors give people a sense of excitement, easy cheerful expression of emotions. Black and white contrasting colors gives a sense of tension and low saturation and gray color gives you a comfortable feeling of harmony. All this with a hint of color on human psychology inseparable relationship, and therefore the site should consider web design web design use of color matching and selection, making it comfortable to the viewer to profound visual experience.

\section{Interface Design Ideas of Wei Yijia Discount Network}

The emergence of a multitude, a variety of shopping sites on the web currently. Wei Yijia discount site for new younger customer groups, to 18--39-year-old young students, young professionals as the main target of the discount sites. Distinguished from traditional shopping website platform, Wei 
Yijia mainly target consumer groups in the most favorable way of discount, select domestic and international high-quality merchandise, fresh, vibrant, saving time and money for the purpose of serving the younger generation groups, to help them in busy life in an affordable way to fun shopping, easy life. According to the website creation purposes, Wei Yijia website design team through investigation domestic e-commerce shopping site page design existing problems, combined with their own advantages and disadvantages of the idea by comparing the domestic and foreign web interface design, a rational analysis of integration, design a site different from domestic shopping web shopping interface, fashion, simple, comfortable Lord and Wei Yijia consumer groups bring different online shopping experience.

After investigation, we found that the first impression gives Europe website design is often simple, the atmosphere, focused, for basic text descriptions often take simple and elegant way, but for larger bodies of text, usually by paragraph composition will their differentiation so as to reduce viewer fatigue reading. For the use of color, depending on the company website web designers in Europe and America will be a different page color combinations, such as Blackberry manufacturing company based on the company's corporate philosophy, adhering to the home page of its overseas web design simple and beautiful features. Home content portion minimal, and modern science and technology as the basis for the full sense of blue background, giving a sense of elegant simplicity. The beginning of the page with a larger BlackBerry to promote its latest products to attract customers attention diagram describes activities related products, the overall layout of the page is simple. Next is a brief introduction of the company's other products, and with the purchase link, viewers can jump directly through a link to another web interface later. By simplifying complex content provision to put two directories, just make a link, you avoid the crowded main page content clutter from happening, make a simple browser user experience is not simple and elegant web interface.

Wei Yijia network interface designed by abandoned traditional domestic network interface design web interface unreasonable distribution, content layout confusing, many of the drawbacks of a simple web interface, clear arrangement design. Home in Pai Tau Wei Yijia exquisite eye-catching slogans to remind viewers location, exquisite photographs and graphic mixed picture on this page to inform viewers of various products (such as: clothing, bags, cosmetics, food, home, etc.) promotions and discounts. To streamline the text links, the main products to be significantly avoided picture distribution page gives a complicated feeling of clutter. Visitors can find the simple site navigation bar Wei Yijia Home want to focus on content classification, you can click into to find interesting bargains plate. Saving time and to avoid the embarrassment of browsing the web can not find the desired information. After all kinds of products to enter the graphic click on the link, the page will be selected according to a combination of the client user's browser area with the best promotions Purchase Program Browse related products, truly for the sake of the consumer customer base - "saving time and money." the founder of the concept of the page.

In web design the color area, Wei Yijia web design team of young customer groups based on psychological trend analysis, the choice of series of youth, vitality candy color tone, to be changed according to different months, different from the general shopping site low, single web interface hue at the same time, always to the viewer with a new visual experience, avoid visual fatigue viewers to fit the younger generation of consumer groups filled with vigor, and to embrace the life attitude, making web browsing while shopping also remind ourselves smile life attitude.

\section{Conclusion}

As people gradually improve web interface design aesthetic needs, the application of visual symbolic elements are more and more important. Thus, Wei Yijia discount network design should take full account of the various elements of visual symbols, combined with web design elements: "Youth", "shopping", "money", designed to sell young people fresh, delicate web interface. 


\section{Acknowledgements}

Chongqing University Students' Creative Entrepreneurship Training Program in 2015: "Wei Yijia " discount network (Item Number: 201514388 399).

\section{References}

[1] Zhang Wangyuan, Chen Jiaojiao. Web design personalized visual symbols [J]. EDUCATION ARTICLE (on Xunkan), 2008, 01: 187 + 189.

[2] Lan Lan. Based on the analysis and study of visual art web interface elements [D]. Hunan University, 2009.

[3] Zhang Siwang. Functional web design visual elements and aesthetic research [D]. Northwestern University, 2006.

[4] Dong Haibin. Research plane visual elements in web design [D]. Xi'an University of Technology, 2008.

[5] Dong Haibin, Wang Limei, Sun Haozhang. Web interface design plane visual elements [J]. Packaging Engineering, 2010, 04: 89-91.

[6] Yang Xihui. Liu Xili. Elements of web design and layout ideas [J]. Decoration, 2005, 04: 56-57. 